\title{
Smoke-free homes, smoking susceptibility and familial smoking among never-smoking high school students: a cross-sectional analysis
}

\author{
Bruce Gregoire BA, Sunday Azagba PhD, Mark Asbridge PhD
}

\section{Abstract}

Background: Research has shown that living in a smoke-free home has a positive effect on adolescents' perceived acceptance of smoking. However, the relationship between smoke-free homes and adolescent smoking behaviours remains unclear. The aim of this study was to examine the association between smoke-free homes and smoking susceptibility among high school students, and to determine whether these associations persist when analyses are stratified by familial smoking status.

Methods: We conducted a random cross-sectional survey (2012/2013 Youth Smoking Survey) of primary, junior and high school students in Canada $(n=47203)$. Multivariable logistic regression analyses were used to examine the associations between smoke-free homes and susceptibility to smoking among never-smoking high school students, with and without stratification by familial smoking.

Results: Analyses showed that adolescents living in a smoke-free home had reduced odds of being susceptible to smoking (odds ratio [OR] 0.582, 95\% confidence interval [Cl] 0.428-0.791) compared with their peers living in households where smoking was permitted. When adolescents had other family members who were smokers, having a smoke-free home was not significantly associated with reduced smoking susceptibility (OR 0.878, 95\% $\mathrm{Cl} 0.721-1.071$ ).

Interpretation: Our results suggest that smoke-free homes may influence future smoking initiation. Optimal success in preventing youth smoking uptake necessitates having a coherent antismoking message between the home smoking environment and familial smoking behaviour.

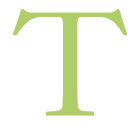

he last decade has seen considerable progress in reducing exposure to second-hand smoke in the home among Canadian youth (age 12-17 yr), dropping from $23 \%$ in 2002 to $7 \%$ in $2012 .{ }^{1}$ Living in a smokefree home has been shown to have positive effects on a range of smoking-related behaviours and health outcomes..$^{2-6}$ Smokers in homes that are partial or fully smoke-free tend to smoke fewer cigarettes per day and have a higher motivation to quit smoking. ${ }^{7,8}$ Meanwhile, nonsmoking members of such households report lower exposure to second-hand smoke, ${ }^{9,10}$ higher overall perceived health and well-being, ${ }^{11}$ and have lower intentions to become future smokers. ${ }^{12}$ Although the literature has shown a consistent relationship between living in a smoke-free home and smoking behaviours among adults, the effect of smoke-free homes on adolescent smoking remains less clear, in part due to an adolescent's inability to control the implementation of smoke-free home rules and the strong influence that adult behaviour plays in modelling smoking behaviour for youth. ${ }^{13,14}$

Smoke-free homes have been linked with a decrease in adolescents' perceived acceptance of smoking; ${ }^{15,16}$ however, findings are mixed on the effects of smoke-free homes on adolescent smoking initiation, maintenance and cessation. ${ }^{17}$ Both longitudinal ${ }^{16}$ and cross-sectional ${ }^{18-21}$ studies have found that adolescents living in smoke-free homes are less likely to start smoking and, among current smokers, have a reduced risk of progression to heavy smoking. At the same time, the relation between smoke-free homes and adolescent smoking may depend on familial smoking status, ${ }^{17}$ with some studies reporting that smoke-free homes only reduce the risk of adolescent smoking in nonsmoking families. ${ }^{16,22}$ Other research finds that the relation between living in a smokefree home and smoking behaviour exists only among adolescents living with parents who smoke, ${ }^{23}$ whereas some studies have found that the association is attenuated after adjustment for parental smoking. ${ }^{24,25}$ Collectively, the varied findings suggest a need to more carefully examine the independent and interactive effects of familial smoking on the association between living in a smoke-free home and adolescent smoking behaviour.

Competing interests: None declared.

This article has been peer reviewed.

Correspondence to: Mark Asbridge, mark.asbridge@dal.ca

CMAJ Open 2016. DOI:10.9778/cmajo.20160010 
This study looks to bridge the gap in the scientific literature with answers to the following questions: Are smoke-free homes associated with reduced smoking susceptibility among never-smoking adolescents; does this association persist after adjusting for familial smoking status; and does the association between smoke-free homes and reduced smoking susceptibility remain after stratification based on familial smoking status?

\section{Methods}

\section{Design}

The Youth Smoking Survey is a nationally representative cross-sectional, biannual classroom-based survey that endeavours to provide estimates of tobacco use rates at national and provincial levels and capture issues influencing tobacco use (knowledge, social influences and attitudes). The 2012-2013 iteration was administered in 9 Canadian provinces (Manitoba declined to participate). Comparative estimates of 2010-2011 Youth Smoking Survey with and without Manitoba found no significant differences in smoking outcomes. ${ }^{26}$

\section{Participants}

The Youth Smoking Survey was administered to 47203 students enrolled in grades 6-12. The cohort was drawn from a random sample of private, public and Catholic schools. Students attending special schools (special needs, visuallyimpaired, military), or attending a school with no eligible grades or no classes with at least 20 students were excluded. The University of Waterloo (the principal coordinator of the Youth Smoking Survey), Health Canada and institutions of consortium members provided ethics approval for all protocols and materials of the Youth Smoking Survey, where required. Dalhousie University (Halifax) provided the ethical approval for this research project.

\section{Measures}

\section{Dependent variable}

Susceptibility to smoking was measured among those who have never tried cigarettes, drawing on answers to 3 questions about smoking intentions from a previously validated scale: ${ }^{27}$ "Do you think in the future you might try smoking cigarettes?"; "If one of your best friends was to offer you a cigarette would you smoke it?"; and "At any time during the next year do you think you will smoke?" Students could respond "definitely yes," "probably yes," "probably not" or "definitely not." If a student provided any response other than "definitely not" to any of the questions, they were classified as a "yes" for smoking susceptibility.

\section{Independent variables}

Smoke-free home was the main variable of interest for predicting susceptibility to smoking. Students could describe the rules in their home using a 4-point nominal scale: "no one is allowed to smoke in the home," "only special guests are allowed," "only in certain areas is smoking allowed" or "smoking is allowed anywhere." Keeping in line with previous research, ${ }^{16}$ "no one is allowed to smoke" represented a smokefree home. We considered all other arrangements as allowing smoking in the home.

A number of covariates previously shown to be associated with smoking behaviours are included in our models. These are student sex, grade (9-12), race (white v. non-white) and academic marks (based on a 5-point scale asking students to best describe their marks in the previous year [ranging from high — "Mostly A's and B's/70\%-84\%/level 3-4," to medium — "Mostly B's and C's/60\%-69\%/level 3," to low — "Mostly C's/50\%-59\%/level 2"]). In addition, the Youth Smoking Survey includes a measure for self-esteem drawing on answers to 3 questions from a validated scale on self-concept: ${ }^{28}$ "In general, I like the way I am," "When I do something, I do it well," and "I like the way I look." For each question, a student could respond using a 5-point Likert scale of "false," "mostly false," "neutral," "mostly true" and "true," with corresponding values of $0-4$, respectively, for a total summed score out of 12. We categorized scores as less than the median $(\leq 8 / 12)$, greater than the median but less than 90th percentile (9 to 11/12), and greater than the 90th percentile (12/12). Familial smoking status was derived from students' responses as to how many of their parents, step-parents, guardians and siblings smoked cigarettes, with responses dichotomized based on having at least 1 family member who smokes versus having no family members who smoke.

\section{Statistical analysis}

Multivariable logistic regression models are employed to assess the associations between smoke-free homes and smoking susceptibility. For analysis, only responses from students in grades 9 and above and students who had never tried or experimented with cigarette smoking were included. In addition, analyses stratified by family smoking status (none v. 1 or more family member who smokes) were performed. Survey weights are employed in all analyses to produce representative population estimates and adjust for the unequal probability of selection and student nonresponse. Survey weights were derived in 2 stages. In the first stage, a weight was created to account for the school selection within health region and school strata. A second weight was calculated to adjust for student nonresponse. The weights were then calibrated to the provincial sex and grade distribution in each province. ${ }^{26} \mathrm{We}$ carried out all analyses using Stata 13.0 ME (StataCorp LP, College Station, Tex.) and a cut-off for significance $(p)$ of 0.05 .

\section{Results}

Completed questionnaires were received from 47203 students, drawn from 1073 schools across 127 school boards, for a participation rate of $72 \%$ (of 65812 eligible students). Of these, 17396 students were identified as never-smoking (Table 1), of which $5101(29.3 \%)$ students were considered susceptible to smoking and 14699 (85.6\%) reported living in a smoke-free home. Significant differences in susceptibility among never-smokers were observed across indicators, with female students, younger students, students with lower self- 


\section{OPEN}

Research

esteem, students with poor grades, and students who came from smoking homes showing a higher smoking susceptibility.

Table 2 shows the results of the multivariable logistic regression examining the association between smoke-free homes and smoking susceptibility. Model 1 adjusted for sex, grade, province, race, self-esteem and academic performance. In addition to model 1 covariates, model 2 adjusted for familial smoking. The results show a significant association between smoke-free homes and susceptibility to smoking in both models. In particular, living in a smoke-free home is associated with lower odds of being susceptible to smoking (odds ratio [OR] $0.687,95 \%$ confidence interval [CI] $0.588-$ 0.804). This association was slightly attenuated after controlling for family member smoking (OR 0.787, 95\% CI 0.664 0.932). In terms of other covariates, a significant increase in the odds of smoking susceptibility was also seen among younger students, students with poor academic performance, and students who report lower self-esteem.

Living in a smoke-free home was not consistently associated with adolescent smoking susceptibility across familial smoking status (Table 3). Among students whose family

\begin{tabular}{|c|c|c|c|}
\hline \multirow[b]{2}{*}{ Characteristic } & \multicolumn{3}{|c|}{ Nonsmokers $(n=17$ 396) } \\
\hline & $\begin{array}{c}\text { Nonsusceptible to } \\
\text { cigarette smoking, } \\
\text { no. }(\%) \\
(n=12295)\end{array}$ & $\begin{array}{c}\text { Susceptible to } \\
\text { cigarette smoking, } \\
\text { no. }(\%) \\
(n=5101)\end{array}$ & $p$ value $^{*}$ \\
\hline \multicolumn{4}{|l|}{ Sex } \\
\hline Female & $6485(68.5)$ & $2672(31.5)$ & 0.003 \\
\hline Male & 5810 (71.9) & $2429(28.1)$ & 0.003 \\
\hline \multicolumn{4}{|l|}{ Grade } \\
\hline 9 & $3503(66.8)$ & 1729 (33.2) & $<0.0001$ \\
\hline 10 & $3483(67.5)$ & $1551(32.5)$ & $<0.0001$ \\
\hline 11 & $3052(73.0)$ & $1128(27.0)$ & $<0.0001$ \\
\hline 12 & 2257 (75.3) & $693(24.7)$ & $<0.0001$ \\
\hline \multicolumn{4}{|l|}{ Province† } \\
\hline Atlantic & $4279(70.9)$ & $1625(29.1)$ & 0.2 \\
\hline Quebec & $1139(72.2)$ & $387(27.8)$ & 0.2 \\
\hline Ontario & $2062(69.2)$ & $915(30.8)$ & 0.2 \\
\hline Saskatchewan & 1501 (68.9) & $706(31.1)$ & 0.2 \\
\hline Alberta & $1498(70.0)$ & $659(30.0)$ & 0.2 \\
\hline British Columbia & 1816 (71.5) & 809 (28.5) & 0.2 \\
\hline \multicolumn{4}{|l|}{ Race† } \\
\hline White & 9317 (69.6) & $3774(30.4)$ & 0.2 \\
\hline Non-white & $2910(71.4)$ & $1284(28.6)$ & 0.2 \\
\hline \multicolumn{4}{|c|}{ Overall self-esteem score } \\
\hline$\leq 8$ & $3735(60.8)$ & 2318 (39.2) & $<0.0001$ \\
\hline $9-11$ & $6400(73.4)$ & $2258(26.6)$ & $<0.0001$ \\
\hline$\geq 12$ & 2126 (79.2) & $509(20.8)$ & $<0.0001$ \\
\hline \multicolumn{4}{|c|}{ Academic performance $\dagger$} \\
\hline Levels 3 and 4 & $10034(71.3)$ & 3792 (28.7) & $<0.0001$ \\
\hline Level 3 & $1611(66.3)$ & $914(33.7)$ & $<0.0001$ \\
\hline Level 2 and lower & $363(59.0)$ & $256(41.0)$ & $<0.0001$ \\
\hline \multicolumn{4}{|c|}{ Any family member smoking $†$} \\
\hline No & $7442(74.1)$ & $2548(25.9 \%)$ & $<0.0001$ \\
\hline Yes & $4246(64.4)$ & $2245(35.6 \%)$ & $<0.0001$ \\
\hline
\end{tabular}


members did not smoke, living in a smoke-free home significantly reduced susceptibility to smoking (OR 0.582, 95\% CI 0.428-0.791). Conversely, among students with familial members who did smoke, living in a smoke-free home was not associated with smoking susceptibility (OR 0.878, 95\% CI $0.721-1.071)$.

\section{Interpretation}

Public health efforts to reduce the impact of smoking have been enhanced in recent years, with the widespread adoption of smoke-free homes working in conjunction with broader restrictions on smoking in other public spaces and other tobacco control measures. Smoke-free homes have been shown to reduce the onset of smoking, which is particularly important among young people given that most long-term smokers initiate tobacco use before 18 years of age. ${ }^{17}$ The cur- rent study finds that living in a smoke-free home is significantly associated with a reduced susceptibility to smoking among students who had never tried or experimented with cigarette smoking. However, stratified analysis suggests that this relationship is contextualized based on familial smoking status. Specifically, the benefits of reduced smoking susceptibility accrued by living in a smoke-free home were only realized if the student's family members were also nonsmokers. If a student had other family members who smoked, living in a smoke-free home was not associated with smoking susceptibility.

Our findings are in line with previous studies that have shown a stronger association between smoke-free homes and lower rates of smoking among youth whose parents do not smoke. ${ }^{16,17,22}$ In a recent review, Emory and colleagues found marginal evidence of an association between smokefree homes and adolescent smoking behaviours, with stron-

\begin{tabular}{|c|c|c|c|c|}
\hline \multirow[b]{3}{*}{ Characteristic (reference category) } & \multicolumn{4}{|c|}{ Susceptibility to initiating smoking } \\
\hline & \multicolumn{2}{|c|}{ Model 1} & \multicolumn{2}{|c|}{ Model 2} \\
\hline & OR estimate & $95 \% \mathrm{Cl}$ & OR estimate & $95 \% \mathrm{Cl}$ \\
\hline \multicolumn{5}{|l|}{ Smoke-free home (smoking permitted) } \\
\hline Completely & $0.687^{*}$ & $(0.588-0.804)$ & $0.787^{*}$ & $(0.664-0.932)$ \\
\hline \multicolumn{5}{|l|}{ Sex (female) } \\
\hline Male & 1.072 & $(0.954-1.205)$ & 1.039 & $(0.920-1.172)$ \\
\hline \multicolumn{5}{|l|}{ Grade (12) } \\
\hline 9 & $1.481^{*}$ & $(1.239-1.770)$ & $1.458^{*}$ & $(1.213-1.753)$ \\
\hline 10 & $1.441^{*}$ & $(1.204-1.726)$ & $1.461^{*}$ & $(1.214-1.759)$ \\
\hline 11 & 1.108 & $(0.914-1.342)$ & 1.129 & $(0.926-1.376)$ \\
\hline \multicolumn{5}{|l|}{ Province (Ontario)† } \\
\hline Atlantic & $0.853^{*}$ & $(0.755-0.965)$ & $0.862^{*}$ & $(0.760-0.979)$ \\
\hline Quebec & $0.708^{*}$ & $(0.580-0.865)$ & $0.729^{*}$ & $(0.592-0.898)$ \\
\hline Saskatchewan & 1.030 & $(0.901-1.178)$ & 1.042 & $(0.907-1.196)$ \\
\hline Alberta & 0.926 & $(0.789-1.087)$ & 0.936 & $(0.793-1.103)$ \\
\hline British Columbia & $0.857^{*}$ & $(0.741-0.990)$ & 0.882 & $(0.759-1.025)$ \\
\hline \multicolumn{5}{|l|}{ Race (non-white)† } \\
\hline White & 1.106 & $(0.968-1.263)$ & 1.093 & $(0.952-1.255)$ \\
\hline \multicolumn{5}{|l|}{ Overall self-esteem score $(\geq 12) \dagger$} \\
\hline$\leq 8$ & $2.240^{*}$ & $(1.847-2.715)$ & $2.198^{*}$ & $(1.802-2.680)$ \\
\hline score 9-11 & $1.317^{\star}$ & $(1.092-1.589)$ & $1.304^{*}$ & $(1.075-1.583)$ \\
\hline \multicolumn{5}{|l|}{ School grade (levels 3 and 4$) \dagger$} \\
\hline Level 3 & $1.231^{*}$ & $(1.067-1.421)$ & $1.191^{*}$ & $(1.027-1.381)$ \\
\hline Level 2 and lower & $1.543^{*}$ & $(1.103-2.160)$ & $1.439^{*}$ & $(1.004-2.061)$ \\
\hline \multicolumn{5}{|c|}{ Any family member who smokes (None)† } \\
\hline$\geq 1$ & $\mathrm{~N} / \mathrm{A}$ & $\mathrm{N} / \mathrm{A}$ & $1.349^{*}$ & $(1.190-1.529)$ \\
\hline
\end{tabular}




\section{OPEN}

Research

ger associations in homes without a family member who is a smoker. ${ }^{17}$ Other studies have found that smoke-free homes are not associated with adolescent smoking behaviour after controlling for parental smoking, ${ }^{24,25}$ though these studies do not provide stratified analyses. O'Loughlin and colleagues, ${ }^{14}$ adopting a slightly different approach, found that smoking onset was significantly higher among young people living in a smoke-free home in which both parents were smokers, compared with homes where neither parent smoked. The authors suggested that young people in these homes likely recognize a disconnect between their parents' smoking behaviours, the larger rules surrounding tobacco use in the home and parents' lack of adherence to their own rules ("do as I say, not as I do"). For this reason, uncertainty is created through the absence of a clear antismoking message, leaving young people more vulnerable to smoking initiation. A similar disconnect was seen in an earlier qualitative study examining messages that teens receive about cigarette smoking. ${ }^{13,29}$

\section{Limitations}

Study data are cross-sectional and only allow for an examination of association; however, in measuring smoking susceptibility, we are examining future intentions, rather than current behaviour, which may help to mitigate some concerns with temporality.

The Youth Smoking Survey contains self-report information that is susceptible to a number of forms of bias, including recall-bias, in which students may inaccurately remember events that occurred in the preceding months or years, and social desirability bias, in which students may respond to questions in a manner that they perceive as being viewed more favourably by others. Both forms of bias may produce errors in estimates, which may inflate (overreporting of positive behaviours) or reduce (underreporting of negative behaviours) measures of association.

Our key exposure measure, smoke-free homes, was measured based on students' understanding of the rules in their house, and there may be discrepancies with the actual house

\begin{tabular}{|c|c|c|c|c|}
\hline \multirow[b]{3}{*}{ Characteristic (reference category) } & \multicolumn{4}{|c|}{ Susceptibility to initiating smoking } \\
\hline & \multicolumn{2}{|c|}{ No family smokers } & \multicolumn{2}{|c|}{ One or more family smokers } \\
\hline & OR estimate & $95 \% \mathrm{Cl}$ & OR estimate & $95 \% \mathrm{Cl}$ \\
\hline \multicolumn{5}{|l|}{ Smoke-free home (smoking permitted) } \\
\hline Completely & $0.582^{*}$ & $(0.428-0.791)$ & 0.878 & $(0.721-1.071)$ \\
\hline \multicolumn{5}{|l|}{ Sex (female) } \\
\hline Male & 1.023 & $(0.871-1.200)$ & 1.058 & $(0.879-1.275)$ \\
\hline \multicolumn{5}{|l|}{ Grade (12) } \\
\hline 9 & 1.228 & $(0.964-1.564)$ & $1.873^{*}$ & $(1.406-2.494)$ \\
\hline 10 & $1.407^{*}$ & $(1.107-1.789)$ & $1.554^{*}$ & $(1.163-2.078)$ \\
\hline 11 & 0.973 & $(0.753-1.258)$ & $1.414^{*}$ & $(1.035-1.931)$ \\
\hline \multicolumn{5}{|l|}{ Province (Ontario)† } \\
\hline Atlantic & 0.889 & $(0.749-1.056)$ & $0.828^{*}$ & $(0.686-0.999)$ \\
\hline Quebec & 0.790 & $(0.597-1.046)$ & $0.657^{*}$ & $(0.482-0.895)$ \\
\hline Saskatchewan & 1.119 & $(0.934-1.340)$ & 0.933 & $(0.751-1.158)$ \\
\hline Alberta & 0.928 & $(0.743-1.158)$ & 0.922 & $(0.717-1.186)$ \\
\hline British Columbia & 0.966 & $(0.795-1.175)$ & 0.789 & $(0.622-1.001)$ \\
\hline \multicolumn{5}{|l|}{ Race (non-white)† } \\
\hline White & $1.259^{*}$ & $(1.050-1.510)$ & 0.867 & $(0.698-1.077)$ \\
\hline \multicolumn{5}{|l|}{ Overall self-esteem score $(\geq 12) \dagger$} \\
\hline$\leq 8$ & $2.021^{*}$ & $(1.578-2.588)$ & $2.729^{*}$ & $(1.970-3.781)$ \\
\hline $9-11$ & 1.140 & $(0.898-1.448)$ & $1.742^{*}$ & $(1.265-2.400)$ \\
\hline \multicolumn{5}{|l|}{ School grade (levels 3 and 4$) \dagger$} \\
\hline Level 3 & 1.080 & $(0.873-1.335)$ & $1.309^{*}$ & $(1.061-1.615)$ \\
\hline Level 2 and lower & $1.526^{*}$ & $(1.024-2.272)$ & 1.400 & $(0.813-2.410)$ \\
\hline $\begin{array}{l}\text { Note: } \mathrm{Cl}=\text { confidence interval, } \mathrm{OR}=\text { odds ra } \\
{ }^{*} \text { Significant at the } p=0.05 \text { level. } \\
\text { †Some missing values for this variable in the }\end{array}$ & Jopulation. & & & \\
\hline
\end{tabular}


rules as articulated by the parents. We attempted to address this possibility with the inclusion of older students only (grade 9 and above) who may have a greater awareness of home smoking rules.

Finally, the Youth Smoking Survey does not contain measures of socioeconomic status (family income or parental educational level) and family structure, which are potential confounders.

\section{Conclusion}

This study makes an important contribution to our understanding of the relationship between smoke-free homes and adolescent smoking behaviours. It suggests that the various components of the home smoking environment - rules, familial smoking behaviours and familial attitudes toward smoking - must not contradict one another if the prevention of smoking initiation among young people is to be effective.

Moving forward, continued research in this area that employs longitudinal designs that account for familial smoking status is required. Such work should employ an updated version of the smoking susceptibility scale, ${ }^{30}$ which now includes a measure of curiosity, which has been shown to improve the prediction of smoking initiation.

\section{References}

1. Overview of historical data, 1999-2012. Table 1. Percentage of current smokers, by age group and sex, age 15+, Canada 1999-2012. Ottawa: Government of Canada; 2013 . Available: http://healthycanadians.gc.ca/publications/healthyliving-vie-saine/tobacco-monitoring-survey-historical-data-2012-enquetesurveillance-tabac-donnees-historique/index-eng.php (accessed 2016 Jan 14).

2. Borland R, Yong H, Cummings KM, et al. Determinants and consequences of smoke-free homes: findings from the International Tobacco Control (ITC) Four Country Survey. Tob Control 2006;15:iii42-50.

3. Hyland A, Higbee C, Travers MJ, et al. Smoke-free homes and smoking cessation and relapse in a longitudinal population of adults. Nicotine Tob Res 2009;11:614-8.

4. Messer K, Mills AL, White MM, et al. The effect of smoke-free homes on smoking behavior in the U.S. Am 7 Prev Med 2008;35:210-6.

5. Shields M. Smoking bans: influence on smoking prevalence. Health Rep 2007;18:9-24.

6. Azagba S, Asbridge M. The association between smoking bans and nicotine dependence: a longitudinal analysis of current smokers in Canada. Addict Behav 2013;38:2817-20.

7. Farkas AJ, Gilpin EA, Distefan JM, et al. The effects of household and workplace smoking restrictions on quitting behaviours. Tob Control 1999;8:261-5.

8. Gilpin EA, White MM, Farkas AJ, et al. Home smoking restrictions: which smokers have them and how they are associated with smoking behavior. Nicotine Tob Res 1999;1:153-62.

9. Biener L, Cullen D, Di ZX, et al. Household smoking restrictions and adolescents' exposure to environmental tobacco smoke. Prev Med 1997;26:358-63.

10. Spencer N, Blackburn C, Bonas S, et al. Parent reported home smoking bans and toddler (18-20 month) smoke exposure: a cross-sectional survey. Arch Dis Child 2005;90:670-4.

11. Asbridge M, Ralph K, Stewart S. Private space second-hand smoke exposure and the mental health of non-smokers: a cross-sectional analysis of Canadian adults. Addict Behav 2013;38:1679-86.

12. Edjoc R. The association between household smoking restrictions and smoking abstinence: does age matter. 7 Smok Cessat 2011;6:74-8.

13. Clark PI, Schooley MW, Pierce B, et al. Impact of home smoking rules on smoking patterns among adolescents and young adults. Prev Chronic Dis 2006;3:Ä1.

14. O'Loughlin JL, Barry AD, O'Loughlin EL, et al. Home smoking bans may increase the risk of smoking onset in children when both parents smoke. Nicotine Tob Res 2014;16:1009-13.
15. Conley Thomson C, Siegel M, Winickoff J, et al. Household smoking bans an adolescents' perceived prevalence of smoking and social acceptability of smoking. Prev Med 2005;41:349-56.

16. Albers AB, Biener L, Siegel M, et al. Household smoking bans and adolescent antismoking attitudes and smoking initiation: findings from a longitudinal study of a Massachusetts youth cohort. Am F Public Health 2008;98:1886-93.

17. Emory K, Saquib N, Gilpin EA, et al. The association between home smoking restrictions and youth smoking behaviour: a review. Tob Control 2010;19:495-506

18. Rodriguez D, Tscherne J, Audrain-McGovern J. Contextual consistency and adolescent smoking: Testing the indirect effect of home indoor smoking restrictions on adolescent smoking through peer smoking. Nicotine Tob Res 2007;9:1155-61.

19. Andreeva TI, Krasovsky KS, Semenova DS. Correlates of smoking initiation among young adults in Ukraine: a cross-sectional study. BMC Public Health 2007;7:106

20. Wakefield MA, Chaloupka FJ, Kaufman NJ, et al. Effect of restrictions on smoking at home, at school, and in public places on teenage smoking: cross sectional study. BM7 2000;321:333-7.

21. Farkas AJ, Gilpin EA, White MM, et al. Association between household and workplace smoking restrictions and adolescent smoking. $7 A M A$ 2000;284:717-22.

22. Jackson C, Henriksen L. Do as I say: parent smoking, antismoking socialization, and smoking onset among children. Addict Behav 1997;22:107-14.

23. Andersen MR, Leroux BG, Bricker JB, et al. Antismoking parenting practices are associated with reduced rates of adolescent smoking. Arch Pediatr Adolesc Med 2004;158:348-52.

24. Fisher LB, Winickoff JP, Camargo CA, et al. Household smoking restrictions and adolescent smoking. Am 7 Health Promot 2007;22:15-21.

25. Komro KA, McCarty MC, Forster JL, et al. Parental, family, and home characteristics associated with cigarette smoking among adolescents. Am 7 Health Promot 2003;17:291-9.

26. Burkhalter R, Cumming T, Rynard V, et al. 2012/2013 Youth smoking survey microdata user guide. Waterloo: Propel Centre for Population Health Impact, University of Waterloo; 2013:1-47.

27. Pierce JP, Choi WS, Gilpin EA, et al. Validation of susceptibility as a predictor of which adolescents take up smoking in the United States. Health Psychol 1996; 15:355-61.

28. Marsh HW, Neill RO. Self-Description Questionnaire III: the construct validity of multidimensional self-concept ratings by late adolescents. $7 \mathrm{Educ}$ Meas 1984;21:153-74.

29. Crawford MA; Tobacco Control Network Writing Group. Cigarette smoking and adolescents: messages they see and hear. Public Health Rep 2001;116(Suppl 1):203-15.

30. Nodora J, Hartman SJ, Strong DR, et al. Curiosity predicts smoking experimentation independent of susceptibility in a US national sample. Addict Bebar 2014;39:1695-700.

Affiliations: Department of Community Health and Epidemiology (Gregoire, Asbridge), Dalhousie University, Halifax, NS; Propel Centre for Population Health Impact (Azagba), School of Public Health and Health Systems, University of Waterloo, Waterloo, Ont.

Contributors: All of the authors contributed substantially to the manuscript. Mark Asbridge and Bruce Gregoire were involved in the conception of the manuscript, Sunday Azagba and Mark Asbridge led the design of the study and the analysis and interpretation of the data. Bruce Gregoire, Sunday Azagba and Mark Asbridge drafted the article. All of the authors gave final approval of the version to be published and agree to act as guarantors of the work.

Disclaimer: The Youth Smoking Survey is a product of the pan-Canadian capacity-building project funded through a contribution agreement between Health Canada and the Propel Centre for Population Health Impact at the University of Waterloo. The Youth Smoking Survey is implemented with the assistance of a consortium of Canadian researchers from all provinces. The views expressed herein do not necessarily represent the views of Health Canada.

Supplemental information: For reviewer comments and the original submission of this manuscript, please see www.cmajopen.ca/content/4/2/ E298/suppl/DC1 